them are siblings, and their mother has proved symptomatic lactose intolerance. The father of another child gave a history of "being unable to digest milk," and a lactose absorption test yielded a flat curve. The fourth child has a persistent disaccharide and monosaccharide intolerance, and continues to get recurrent bouts of diarrhoea and has a poor weight gain.

\section{Discussion}

Carbohydrates in the form of polysaccharide starch and disaccharide sugars provide the bulk of calories in a normal diet. Each of these has to undergo enzymatic hydrolysis to monosaccharides before substantial absorption can occur. The enzymes involved in the process reside in the epithelial cells of small-intestinal mucosa, although their exact intracellular location-in the brush border alone or in the cytoplasm as wellis a subject of debate. The intestinal epithelium has the very rapid turnover rate of about 48 hours, and the superficially located enzymes are therefore very vulnerable to damage by a wide variety of noxious influences, thereby producing acquired disaccharidase deficiency (Laster and Ingelfinger, 1961; Townley, 1966). Lactase activity, which is normally lower than that of maltase and sucrase, gets hit first and most frequently. Lactose intolerance can thus occur without any significant alteration in the other enzymes. Lactase is also the last disaccharidase to recover (Kerpel-Fronius et al., 1966). Intestinal epithelial damage is a recognized result of protein-calorie malnutrition (Zubirán, 1961 ; Amin, 1966), enteropathogenic organisms, and intestinal parasites (Bowie et al., 1965 ; KerpelFronius et al., 1966).

The mechanism through which disaccharide intolerance produces diarrhoea is twofold. Unabsorbed sugar draws water into the lumen of the gut through osmosis, thereby acting as a cathartic with almost one-fifth the potency of magnesium sulphate. Unabsorbed sugar is also acted upon by colonic bacteria, resulting in the production of irritant low-molecularweight organic acids. Both these factors increase peristaltic activity and reduce transit time. The continued presence of unsplit sugars in the gut may damage the epithelial cells further (Holzel et al., 1962 ; Rey et al., 1963), perpetuating and aggravating the enzymic deficiency. These pathophysiological changes could be responsible for malabsorption of other substances, such as D-xylose and fat, as seen in the present study.
The diagnosis of disaccharide intolerance is made on the presence of acid stools, high faecal lactic acid, flat absorption curve, gastrointestinal symptoms on sugar load, and relief on exclusion of the offending carbohydrate. The stools are characteristically large, yellowish-green, frothy, rancid, loose, or watery, and contain shreds of fine mucus (Chandra et al., 1968). Enzyme assays on mucosal biopsies yield a wide range of values and are potentially fallacious because values are necessarily expressed as a function of the whole biopsy specimen rather than that of epithelial cells to which the enzymes are confined (Townley, 1966).

The persistence of lactose intolerance after nutritional recovery and its familial occurrence in three of the four patients in the present series suggests consideration of a primary enzymic defect with consequent diarrhoea and secondary malnutrition. All four patients were under 8 months of age, and their symptoms dated back to the postnatal period. In the fourth child there is a possibility of primary monosaccharide intolerance.

The study was supported in part by the Indian Council of Medical Research.

\section{REPERENCES}

Amin, K. (1966). Small Bowel Studies in Malnutrition and Hypoproteinemia. Thesis for M.D. New Delhi.

Bardare, M., Buitoni, P., and Careddu, P. (1965). Minerva pediat., 17, 832 .

Bowie, M. D., Brinkman, G. L., and Hansen, J. D. L. (1965). J. Pediat., 66, 1083 .

Careddu, P., Giovannini, M., and Cevini, G. (1963). Helv. paediat. Acta, 18, 97.

Cevini, G., Giovannini, M., and Careddu, P. (1962). Minerva pediat., 14, 831 .

Chandra, R. K., Pawa, R. R., and Ghai, O. P. (1968). Indian f. med. Res. In press.

Dean, R. F. A. (1957). Mod. Probl. Paediat., 2, 133.

Ghai, O. P., and Sandhu, R. K. (1968). Indian Y. Pediat., 35, 91.

Holzel, A., Mereu, T., and Thomson, M. L. (1962). Lancet, 2, 1346.

Kerpel-Fronius, E., Jáni, L., and Fekete, M. (1966). Ann. paediat. (Basel), 206, 245 .

Laster, L., and Ingelfinger, F. J. (1961). New Engl. 7. Med., 264, 1138. Rey, J., Frézal, J., Jos, J., Bauche, P., and Lamy, M. (1963). Arch. tranc. pediat.", 20,381 .

Roe, J. H., and Rice, E. W. (1948). 7. biol. Chem., 173, 507.

Townley, R. R. W. (1966). Pediatrics, 38, 127.

Trowell, H. C., Davies, J. N. P., and Dean, R. F. A. (1954). Kwashiorkor. London.

van de Kamer, J. H., ten Bokkel Huinink, H., and Weyers, H. A. (1949). 7. biol. Chem., 177,347 .

Zubirán, S. (1961). Amer. 尹. dig. Dis., 6, 336.

\title{
Dependence on Hypnotic Drugs in General Practice
}

\author{
JOHN JOHNSON,* M.D., M.R.C.P.ED., D.P.M.; A. D. CLIFT, † M.B., M.R.C.G.P., D.R.C.O.G.
}

\begin{abstract}
Simmary : Of the patients in an industrial general practice $\mathbf{1 . 3 \%}$ required hypnotic drugs regularly. They were predominantly in the older age groups (mean 62.7 years), with an excess of widows. Only $0.02 \%$ were severely dependent; the remainder were mildly so, though they had been taking hypnotics for long periods (mean 5.6 years). There were three main original indications for hypnotics-namely, medical (pain), psychiatric, and onset insomnia in anxious personality disorder. Onefifth of the patients first took hypnotics while in hospital. The group as a whole manifested a high degree of abnormal psychological disposition.

It is suggested that many patients who take hypnotics regularly may be placebo reactors, and a more critical attitude to hypnotic prescribing is required both in hospital and in general practice.
\end{abstract}

Concern is repeatedly expressed about the steep rise in the consumption of hypnotic drugs, particularly barbiturates, during the past 15 years (Brit. med. F., 1965), and the fact that they constitute about one-fifth of all N.H.S. prescriptions (Brooke and Glatt, 1964). This has been reflected in the increase in incidents of self-poisoning by hypnotic drugs over the past 10 years (Kessel, 1965), and in the development of dependence on them (Bewley, 1968).

Mild and severe states of dependence on barbiturates are wellrecognized complications (Jaffe, 1965), but their incidence in the population and the degree of risk and frequency with which

\footnotetext{
* Senior Lecturer, University Department of Psychiatry, Manchester Royal Infirmary.

† General Practitioner, Middleton, Manchester.
} 
mild dependence can escalate to severe dependence are undefined. Some indication of the incidence of the latter can, however, be obtained from studies of admissions to psychiatric units. Ewing and Bakewell (1967) found that $7.6 \%$ of all admissions to an American general psychiatric unit were quite dependent on this group of drugs, while Whitlock and Lowrey (1967) in a similar study in Australia found $15 \%$ of all psychiatric admissions dependent on barbiturates. Though studies on amphetaminedependence in this country are available (Johnson and Milner, 1966), there have been no similar studies of depressant-drug dependence in British psychiatric units.

Repeat prescriptions for hypnotic drugs are common in general practice, and this repetition implies that some degree of dependence must have developed. In a study of barbiturate prescriptions in a London practice of 10,000 patients Adams et al. (1966) found that $2 \%$ had been receiving barbiturates regularly for longer than one year, and there was evidence of increasing tolerance in 47 patients, in all of whom associated psychiatric diagnosis had been made. The present study concerns patients who receive repeat prescriptions for hypnotic drugs in general practice, and was undertaken firstly to define the extent of this problem, secondly to investigate the origin of the hypnotic habit, and thirdly to assess the degree of dependence which developed in these patients and the risk of escalation to severe drug dependence. It is widely held by general practitioners that many patients begin to depend on hypnotic drugs after a period in hospital, where they are first introduced to "sleeping tablets." As a subsidiary aim to this investigation, therefore, the rate of hypnotic-prescribing for hospital patients was studied and an assessment of dependence after discharge was made.

\section{Method}

The study took place in a general practice in the north Manchester industrial belt comprising 7,500 patients shared by three G.P.s. All patients in the practice who had been receiving repeat prescriptions for hypnotic drugs for longer than three consecutive months were written to and asked to attend the surgery for a joint interview by us. Seventy-seven patients were interviewed at the surgery and a further 20 were seen at their homes because of some physical disability. The purpose of the semistructured interview was explained to the patients, and information from their medical records was incorporated in the final assessment.

\section{Findings}

At the commencement of the study 97 patients $(1.3 \%$ of practice population) were receiving repeat prescriptions for hypnotic drugs, 74 were receiving barbiturates, and 23 were receiving non-barbiturate hypnotics such as nitrazepam (Mogadon) or glutethimide (Doriden). In order to widen the applicability of our findings, four other general practitioners were asked to supply data on their prescribing habits regarding hypnotic drugs (Table I). The incidence of repeat prescriptions for hypnotics in those practices was similar to that of the practice reported here. The mean age of our patients was high, as shown in Figs. 1 and 2 (62.7 years, S.D. 11.8). The mean age when hypnotics were first taken regularly was 55.5 years (S.D. 14.2), while the mean duration of taking regular hypnotics was 5.6 years (S.D. 16.2) (Fig. 3). The male: female ratio for the whole practice was $1: 1.1$, compared with $1: 2.6$ in those taking hypnotics. This excess of females in the hypnotic-dependent group was significantly in excess of the number of females in an age-matched control group drawn from the practice by the method described by Kessel $(1962)(P<0.1)$. The number of widows in the group was also significantly increased, compared with the expected incidence derived from the 1966 Census sample for the area (Table II).
TABLE I.-Incidence of Repeat Hypnotic Prescriptions in General Practice

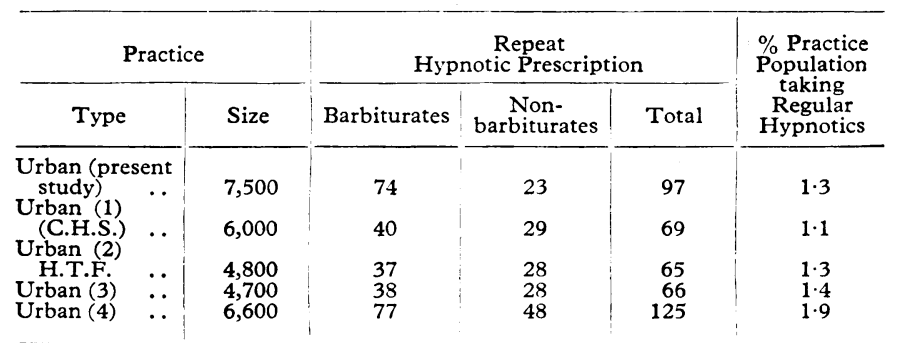

TABLE II.-Sex and Marital Status of Patients Receiving Regular

\begin{tabular}{|c|c|c|c|c|c|}
\hline \multicolumn{3}{|c|}{ Marital Status } & Female & Male & Total \\
\hline $\begin{array}{ll}\text { Married } . . & \ldots \\
\text { Single } & \ldots \\
\text { Widowed } * & \ldots \\
\text { Separated/divorced }\end{array}$ & $\begin{array}{l}\ldots \\
\cdots \\
\cdots\end{array}$ & $\begin{array}{l}\ldots \\
\cdots \\
\cdots\end{array}$ & $\begin{array}{c}35 \\
5 \\
25^{*} \\
5\end{array}$ & $\begin{array}{r}21 \\
0 \\
\dot{0} \\
0\end{array}$ & $\begin{array}{r}56 \\
5 \\
31 \\
5\end{array}$ \\
\hline Total & .. & .. & 70 & 27 & 97 \\
\hline
\end{tabular}

* The number of widows in this population is significantly increased compare with the number of widows in the married female population for the area according with the number of widows
to the 1966 Census sample.

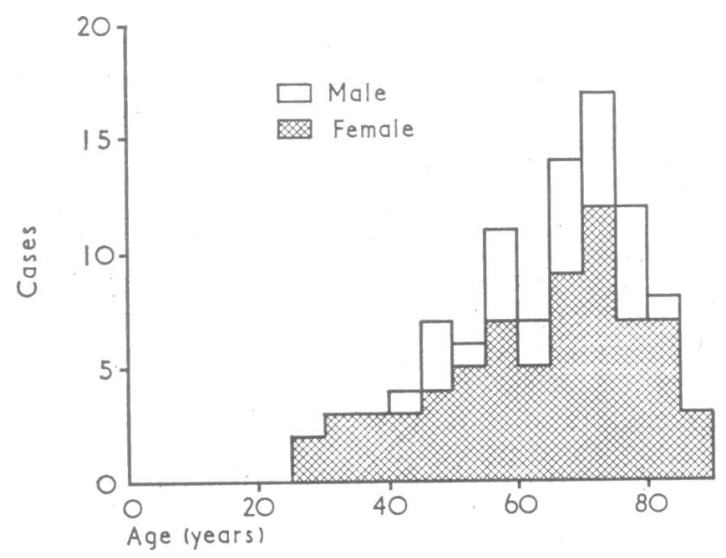

FIG. 1.-Age incidence in patients requiring repeat hypnotics in general practice.

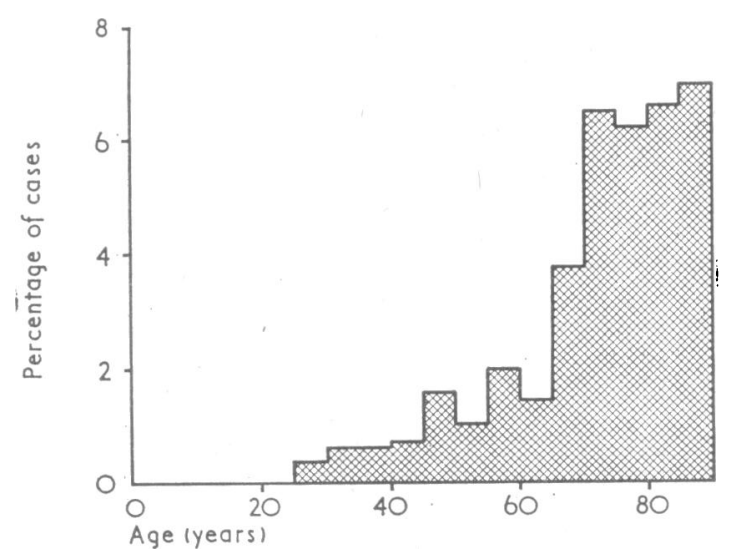

FIG 2.-Prevalence of patients requiring repeat hypnotics in general practice.

Of the hypnotics prescribed, short- and medium-acting barbiturates were most common (Table III), constituting $76 \%$ of the total. Of the non-barbiturate hypnotics ( $24 \%)$, nitrazepam was most frequently prescribed, and probably reflected the change in prescribing habits towards non-barbiturates. Mild dependence on hypnotic drugs was considered to be present if the patient during interview expressed concern that adequate sleep would not be possible without hypnotic drugs, and that anxiety and tension would thereby develop. Severe depen- 


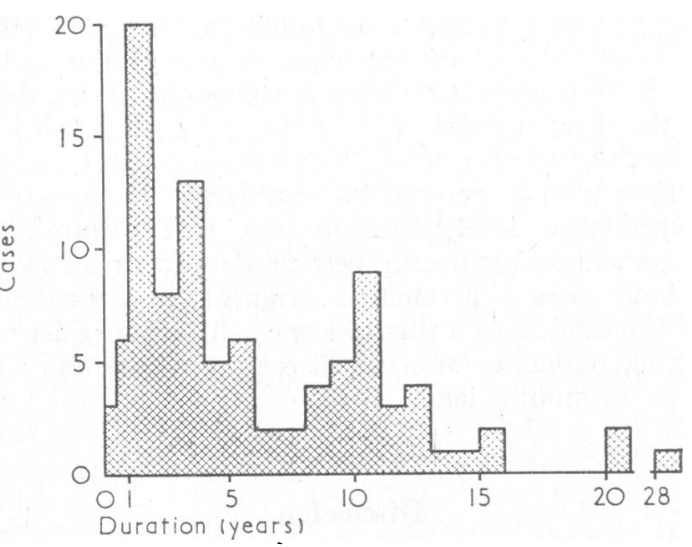

FIG. 3.-Duration of hypnotic-drug dependence.

dence, on the other hand, was diagnosed in keeping with the W.H.O. (1964) definition of drug dependence of barbiturate type. This was considered to be present when there was or had been evidence of increasing tolerance to the hypnotic from the use of increasing quantities, coupled with the effects of periodic intoxication and also abstinence symptoms after withdrawal. Only two cases were regarded as severely dependent: a young woman with a personality disorder who had been periodically intoxicated with barbiturates and had profound marital and social problems. A second woman, aged 83, developed increasing tolerance to barbiturates after an initial moderate prescription of hypnotics 20 years previously. In this case a subsequent cerebral thrombosis with residual brain damage may have accounted for the reduced sleep time and the need for increase in hypnotics (Feinberg, 1967). Of the remaining 95 cases it was possible, with the patients' agreement, to at once discontinue barbiturates in four and non-barbiturates in two, while 10 patients taking barbiturates were changed to nonbarbiturates. Thus 91 patients $(94 \%)$ remained mildly dependent on hypnotics.

Table III.-Type and Dosage of Hypnotic Drugs

\begin{tabular}{|c|c|c|c|c|c|}
\hline \multicolumn{3}{|c|}{$\begin{array}{c}\text { Barbiturate Hypnotics } \\
\text { (Short/Medium Duration) }\end{array}$} & \multicolumn{3}{|c|}{$\begin{array}{c}\text { Non-barbiturate } \\
\text { Hypnotics }\end{array}$} \\
\hline \multicolumn{3}{|c|}{ mg. nocte } & \multirow{2}{*}{$\begin{array}{l}\text { Nitrazepam } \\
\text { 5-10 mg. }\end{array}$} & \multirow{2}{*}{$\begin{array}{l}\text { Glutethimide } \\
250 \mathrm{mg} .\end{array}$} & \multirow{2}{*}{ Others } \\
\hline $100-200$ & $200-400$ & $400-600$ & & & \\
\hline 58 & 15 & 1 & 15 & 6 & 2 \\
\hline \multicolumn{3}{|c|}{$76 \%$} & \multicolumn{3}{|c|}{$24 \%$} \\
\hline
\end{tabular}

\section{Indications for Hypnotic Drugs}

Three distinct groups of indications for hypnotics were identified.

Medical.-In 48 cases the hypnotic had been originally prescribed for insomnia associated with some general medical or surgical disorder. In 26 insomnia was secondary to pain due to chronic musculoskeletal disorders-for example, osteoarthritis, rheumatoid arthritis. This was the biggest single indication for hypnotics. In over half of these cases the patients had exhibited lifelong personality traits of anxious, worrying, sensitive types (Table IV). In a further 22 cases hypnotics were prescribed for the relief of insomnia associated with cardiorespiratory and cerebrovascular disease.

Psychiatric.-The second main indication for hypnotics was for insomnia occurring in association with a psychiatric illness (30 cases). In 20 cases insomnia had started in relation to some situational crisis which led to depressive-anxiety reactions, often requiring treatment on their own account. The most common precipitating event among them was the death of a husband (10 cases), while in a further two cases dependence on hypnotics began after a serious illness in a near relative. In the remaining 10 cases insomnia had started during an episode of endngenous depression.
TABLE IV.-Indication for Original Hypnotic Prescription and Fersonality Assessment

\begin{tabular}{|c|c|c|c|c|c|c|}
\hline \multirow{2}{*}{\multicolumn{2}{|c|}{ Indication }} & \multicolumn{4}{|c|}{ Personality Type } & \multirow[b]{2}{*}{ Total } \\
\hline & & Anxious & $\begin{array}{l}\text { Anan- } \\
\text { castic }\end{array}$ & $\begin{array}{c}\text { Hys- } \\
\text { terical }\end{array}$ & Normal & \\
\hline Medical & $\begin{array}{l}\text { Pain }\left\{\begin{array}{l}\text { Skeletal } \\
\text { Other } \\
\text { Cerebral disease } \\
\text { Cardio-respiratory }\end{array}\right.\end{array}$ & $\begin{array}{l}7 \\
3 \\
2\end{array}$ & & 1 & $\begin{array}{r}11 \\
4 \\
4\end{array}$ & $\begin{array}{r}18 \\
8 \\
6\end{array}$ \\
\hline $\begin{array}{l}\text { Psychia- } \\
\text { tric } \\
\text { Onset insc }\end{array}$ & $\begin{array}{l}\text { disease } \\
\text { Endogenous depressio } \\
\text { Reactive depression } \\
\text { mnia } . .\end{array}$ & $\begin{array}{r}4 \\
4 \\
18 \\
12\end{array}$ & $\begin{array}{l}1 \\
1 \\
0 \\
1\end{array}$ & $\begin{array}{l}1 \\
1 \\
1 \\
3\end{array}$ & $\begin{array}{r}10 \\
4 \\
1 \\
3\end{array}$ & $\begin{array}{l}16 \\
10 \\
20 \\
19\end{array}$ \\
\hline
\end{tabular}

Onset Insomnia.-The third and smallest group who required hypnotics were 19 patients who complained only of difficulty in falling to sleep (onset insomnia), leading, if unrelieved, to anticipatory anxiety about the consequences of this lack. Insomnia in this group was overwhelmingly associated with abnormal personality developments, and the actual complaint of insomnia was frequently viewed as an overvalued idea.

The importance of the basic personality organization in relation to sleep is seen in the high incidence $(63 \%)$ of abnormal personalities in the total group of patients. The incidence of a previous psychiatric illness, treated either in hospital or in general practice, was high $(43 \%)$. It was compared with the incidence of similar illnesses in a control group, matched for age with the hypnotic-dependent group and chosen from the practice records by the method previously indicated. This confirmed that the incidence of a previous psychiatric illness in those taking regular hypnotics was highly significant (Table V). Further evidence of this abnormal psychic predisposition is the high incidence of psychiatric illness in these patients. Of the 97 patients 42 had had a psychiatric illness, and this had been of an affective type in 36 (Table VI) ; 23 of them had been treated in general practice while 19 were referred to a psychiatric department ; 9 of the latter required electric convulsion therapy. Further manifestations of the frequency of affective disorder in this group were self-poisoning in nine cases $(9.3 \%)$ and self-injury in one ; in three of these the incidents had been multiple. All these incidents occurred while the patients were taking hypnotics originally prescribed after a psychiatric illness.

TABLE V.-Comparison of Psychiatric Illnesses in Hypnotic-dependent Patients and an Age-matched Control Group from Same Practice

\begin{tabular}{|c|c|c|c|c|c|c|}
\hline \multirow{2}{*}{ Group } & & \multirow{2}{*}{ No. } & \multicolumn{2}{|c|}{ Sex } & \multirow{2}{*}{$\begin{array}{c}\text { Psychiatric } \\
\text { Illness Treated } \\
\text { by G.P. }\end{array}$} & \multirow{2}{*}{$\begin{array}{c}\text { Psychiatric } \\
\text { Illness Treated } \\
\text { in Hospital }\end{array}$} \\
\hline & & & $\mathbf{M}$ & $\mathbf{F}$ & & \\
\hline 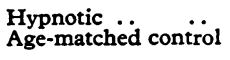 & $\because$ & $\begin{array}{l}97 \\
97\end{array}$ & $\begin{array}{l}27 \\
35\end{array}$ & $\begin{array}{l}70 \\
62\end{array}$ & $\begin{array}{l}23 \\
13\end{array}$ & $\begin{array}{r}19 \\
4\end{array}$ \\
\hline & & & & & \multicolumn{2}{|c|}{ Highly significant. $P<0.001$. } \\
\hline
\end{tabular}

TABLE VI.-Incidence and Type of Psychiatric Disorders in Hypnoticdependent Patients

\begin{tabular}{|c|c|c|c|}
\hline & & $\begin{array}{l}\text { Treated by } \\
\text { G.P. }\end{array}$ & $\begin{array}{c}\text { Treated at Hospital } \\
\text { Psychiatric Department }\end{array}$ \\
\hline $\begin{array}{l}\text { Manic-depressive psycho } \\
\text { Depressive neurosis } \\
\text { Hypochondriacal neurosi } \\
\text { Organic psychoses }\end{array}$ & $\begin{array}{l}\text { lepression } \\
\because \\
\because\end{array}$ & $\begin{array}{r}5 \\
14 \\
0 \\
4\end{array}$ & $\begin{array}{r}13 \\
4 \\
2 \\
0\end{array}$ \\
\hline Total & $\ldots$ & 23 & 19 \\
\hline
\end{tabular}

The close association of the hypnotic drug habit and physical or psychiatric illness is evident in the number who were also taking some drug other than a hypnotic. Nineteen patients were taking analgesics either in combination with a hypnotic-for example, Sonalgin-or as a separate preparation. Twenty-five were taking psychotropic drugs such as minor tranquillizers or antidepressives ; in six cases barbiturates were taken as tranquillizers during the daytime; 16 patients were taking drugs 
for the relief of cardiorespiratory disease; two were taking steroids, and two hypotensive drugs. Only 38 patients were taking hypnotics alone.

In order further to establish the identity of these three groups of patients based on the original indication for hypnotics, the age distributions of each group were compared by an analysis of variance (Table VII). This showed the differences between the group means to be highly significant. In addition, the mean age of onset of taking hypnotics in all these patients was compared with the age of onset of taking hypnotics in 10 severe barbiturate-dependent patients who had been referred to a psychiatric clinic for treatment. A highly significant difference in mean age of onset of the hypnotic habit was clearly present in these two groups.

TABLE VII.-Intergroup Comparisons of Age of Onset for Taking Hypnotics According to Indications: Comparison with Independent Group of Patients with Severe Barbiturate Dependence

\begin{tabular}{|c|c|c|c|c|c|}
\hline & Medical & $\begin{array}{c}\text { Onset } \\
\text { Insomnia }\end{array}$ & $\begin{array}{c}\text { Psy- } \\
\text { chiatric }\end{array}$ & $\begin{array}{c}\text { Total } \\
\text { Hypnotic } \\
\text { Group }\end{array}$ & $\begin{array}{c}\text { Severe } \\
\text { Barbiturate } \\
\text { Dependence }\end{array}$ \\
\hline No. & 48 & 19 & 30 & 97 & 10 \\
\hline $\begin{array}{l}\text { Mean age (yrs.) } \\
\text { onset of hypnotics }\end{array}$ & $62 \cdot 1$ & 53.7 & $50 \cdot 3$ & 55.5 & 23.4 \\
\hline S.D. & 11.5 & 14.9 & $16 \cdot 2$ & $14 \cdot 2$ & $7 \cdot 8$ \\
\hline
\end{tabular}

Difference in group means by analysis of variance is highly significant: $P<0.01$.

\section{Hypnotic Dependence after Stay in Hospital}

Hypnotic dependency had started after an illness in hospital in 21 patients $(21.6 \%)$. In 12 this illness was of a purely physical nature, while in nine it was psychiatric. The continued dependence on hypnotics after physical illness in hospital seemed justified, since most of the conditions persisted in a chronic form-for example, cervical disc lesion, nocturnal dyspnoea. In those cases related to a psychiatric admission, however, the original illness had subsided in all but one and insomnia persisted as a residual symptom.

In order to explore the possibility that some form of drug dependence commences after hypnotics are prescribed in hospitals, a subsidiary investigation was carried out. The prescription sheet of consecutive patients discharged from psychiatric, medical, and surgical units of the Manchester Royal Infirmary between October and December 1966 were examined for the rate of hypnotic prescribing (Table VIII). During their inpatient stay $86 \%$ of psychiatric, $58 \%$ of medical, and $32 \%$ of surgical patients received hypnotic drugs. (Hypnotics prescribed as premedication were discounted.) A large proportion of all groups were discharged from hospital and were not referred back to their general practitioner. Where hypnotics were continued on discharge the subsequent medical records were examined to find how many still required these drugs, and where this was not possible the general practitioner was written to for information on the subsequent necessity for them.

TABL B VIII.-Frequency of Hypnotic Prescribing in Hospital Patients

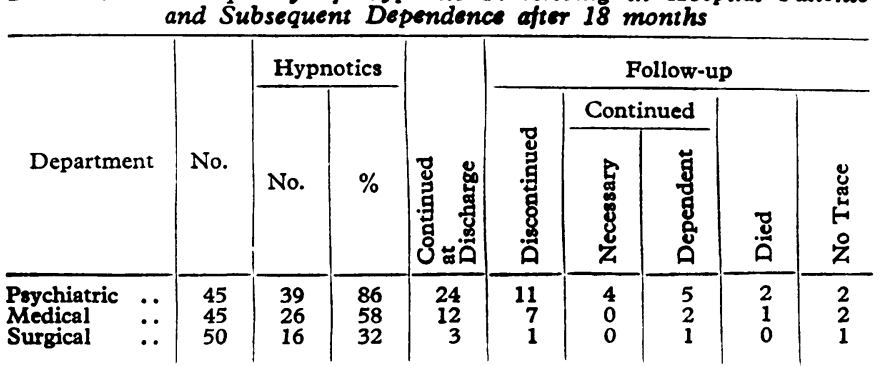

The psychiatric patients, as might be expected, had the highest incidence of continued hypnotic prescriptions after discharge. In four cases hypnotics were thought to be a necessary part of the drug therapy of an active psychotic illness. The remaining five had all received hypnotics before admission, and were suffering from personality disorders. No new cases of drug dependence developed from this small sample. Two medical patients subsequently became dependent on hypnotics, but in both cases a psychiatric diagnosis had been made in hospital in addition to a physical one. Three surgical patients were taking hypnotics after discharge, of whom one v:as still dependent 18 months later.

\section{Discussion}

Drug dependence of barbiturate type is defined by the W.H.O. (1964) as a strong desire to continue the drug, with a tendency to increase dosage, to increasing tolerance, and ultimately to psychic and physical dependence with a self-limiting abstinence syndrome after withdrawal. This type of severe dependence was present in only two patients. In the remaining 95 cases only subjective psychic dependence could be said to be present even after many years. Barbiturates were the most popular hypnotic prescribed $(76 \%)$, but were given at less than $400 \mathrm{mg}$. per night except in one case (Table III). There was some indication that in recent years a change in prescribing habits had occurred, and non-barbiturates, particularly nitrazepam, were being prescribed increasingly in preference to barbiturates.

The absence of increasing tolerance to barbiturates even after many years in this study is, however, in keeping with the findings of Fraser et al. (1958) and Shideman (1961). The former, using volunteer subjects, showed that up to $200 \mathrm{mg}$. of pentobarbitone per day could be taken for many months without increasing tolerance of physical dependence. Only with doses in excess of $600 \mathrm{mg}$. per day did such complications develop. Another explanation for the absence of physical tolerance to barbiturates in these patients may be that the induction of sleep depends not so much on pharmacological properties of the drug as on the reduction in anxiety about sleep through a "placebo reaction." The further investigation of these patients as possible placebo reactors is necessary.

Severe dependence on hypnotic drugs begins in the second and third decade in those with neurotic personality disorders who request hypnotics for insomnia and the symptomatic relief of tension symptoms. In such a group of severely dependent patients who had been referred to a university psychiatric clinic in the past year the mean age of onset of the hypnotic habit was 23.4 years (S.D. 7.8) (Table VII). When the age of onset in this group is compared with the age of onset of the population of regular hypnotic takers in general practice a highly significant difference is found. It would be justifiable to conclude that patients who are severely dependent on hypnotics are not derived from those who regularly take them in general practice. It is the young person with psychiatric symptoms who requests hypnotics who should be suspected of impending or established dependency.

The majority of patients who receive regular hypnotics in the community are in the middle and older age groups. This finding parallels that of Adams et al. (1966), who included in their study all patients requiring hypnotics in general practice as opposed to repeat prescriptions as in ours. The high proportion of elderly patients among those who require regular hypnotics is partly in keeping with the findings of Tune (1968), who observed the breakdown of the consolidated sleep pattern in the elderly and the tendency to compensate for reduction in nocturnal sleep by day-time naps.

Consideration of the original reason for requiring hypnotics led to the identification of three distinct groups-medical, psychiatric, and onset insomnia (Table IV). From analysis of 
their respective ages when first taking hypnotics this distinction appears to be valid. The largest group were those with insomnia in association with some general medical disorder, particularly of a painful nature-for example, osteoarthritis and rheumatoid arthritis. Though hypnotic drugs, particularly barbiturates, are thought not to affect pain perception (Shideman, 1961), such analgesic properties as they possess may be due to their ability to reduce anxiety which develops in anticipation of pain. Such an explanation may well be relevant, particularly as half these patients had shown signs of anxietyprone personality. The presence of lowered pain thresholds in psychiatric patients may also be responsible for the development of insomnia in this group (Merskey and Spear, 1967).

The second largest group of patients were those who commenced habitual hypnotics after a psychiatric illness (Table VI). These were mainly affective disorders, particularly depressive neuroses occurring in patients with personalities of an anxious, insecure type: bereavement of a near relative, particularly a husband, was the most common precipitant of these (Table VI). In an equal number depressive illness had been of an endogenous type and required hospital treatment in two-thirds. Though insomnia in depressive illness is usually of a mixed type (Hinton, 1963), the residual sleep disorder in these patients was invariably of an onset type and persisted after other depressive symptoms had subsided. Lasagna (1962) has emphasized how depressed patients frequently overestimate the passage of time, particularly in relation to how long they claim to "lie awake." Such experiences may form the basis for the development of anxiety about sleep as an overrated idea in these patients.

The third and smallest group were those who simply complained of onset insomnia with marked anticipatory anxiety (Table IV). The majority showed neurotic personality disorders in the setting of which insomnia was a central preoccupation. It would seem in this group particularly that simple psychotherapy plus the use of short-term minor tranquillizers was more appropriate than regular hypnotics.

In deciding on the use of hypnotics the harmful effects of sleep deprivation, particularly in psychiatric patients (Oswald, 1962), and the relief of pain and anxiety in the elderly and those of anxious constitution must be weighed against the possibility of dependence, the risks of self-poisoning, and the availability of other methods to assuage the patient's distress. Psychic dependence apart, the risk of severe dependence seems small from this study, although the same cannot be said for the risk of deliberate self-poisoning with hypnotics which already had occurred in $9 \%$. If regular hypnotics are necessary for short periods then regular surveillance of the patient is obligatory and the use of non-barbiturate hypnotics is to be recommended. Though prescribing habits are changing, barbiturates are still the most popular hypnotics. Hinton (1961) has thrown doubt on the distinction between short- and medium-acting barbiturates, while there is some evidence that barbiturates suppress dreaming during sleep. Detre (1966) has argued that as a result barbiturates are "antitherapeutic," particularly in depressive states, and non-barbiturates, especially the benzodiazepines, are to be preferred. The risks of dependence, both mild and severe, still exist, however, with non-barbiturate hypnotics (Essig, 1964), although their lethal potential, if abused in selfpoisoning, is certainly less than with barbiturates.

The excess in the incidence of psychiatric illness in these patients compared with an age-matched control group, plus the high proportion of patients showing evidence of abnormal basic personalities, emphasizes the abnormal psychological disposition of those in the community who take hypnotics regularly. It would justify the challenge that many of these patients are in fact " placebo reactors," and that other methods of treatment, such as supportive psychotherapy and short-term tranquillizers, might be more effective, less costly, and carry less risk of abuse than the repetitive hypnotic. The onset of the hypnotic habit in over one-fifth of these patients after a period in hospital is a reason for a serious claim for review of prescribing habits, particularly in psychiatric and general medical wards. Indeed, a more critical attitude, both in hospital and in community practice, to repeat hypnotic prescribing is indicated.

We wish to thank Drs. C. H. Strachan, H. T. Fay, T. A. Lambros, and B. L. Alexander for help in supplying data on the prescription of hypnotic drugs in general practice, and Professor Neil Kessel for his helpful criticism of the study.

\section{REFERENCES}

Adams, B. G., Horder, E. J., Horder, J. P. Modell, M., Steen, C. A., and Wigg, J. W. (1966). F. Coll. gen. Practit., 12, 24.

Bewley, T. H. (1968). Proc. roy. Soc. Med., 61, 175.

Brit. med. F., 1965, 2, 1325.

Brooke, E. M., and Glatt, M. M. (1964). Med. Sci. Lazo., 4, 277.

Detre, T. (1966). Canad. psychiat. Ass. F., 11, Spec. Suppl., p. 169.

Essig, C. F. (1964). Clin. Pharmacol. Ther., 5, 334.

Ewing, J. A., and Bakewell, W. E. (1967). Amer. J. Psychiat., 123, 909.

Frases, H. F., Wikler, A., Essig, C. F., and Isbell, H. (1958). ¥. Amer. med. Ass., 166, 126.

Feinberg, I. (1967). Ass. Res. nerv. Dis. Proc., 45, 211.

Hinton, J. M. (1961). Brit. F. Pharmacol., 16, 82.

Hinton, J. M. (1963). F. Neurol. Neurosurg. Psychiat., 26, 184.

Jaffe, J. H. (1965). In Pharmacological Basis of Therapeutics, 3rd ed., edited by L. S. Goodman and A. Gilman, p. 285. London.

Johnson, J., and Milner, G. (1966). Acta psychiat. scand., 42, 252.

Kessel, W. I. N. (1962). In The Burden on the Community, p. 13. London.

Kessel, N. (1965). Brit. med. F., 2, 1265.

Lasagna, L. (1962). Proc. roy. Soc. Med., 55, 773.

Merskey, H., and Spear, F. G. (1967). Pain, Psychological and Psychiatric Aspects. London.

Oswald, I. (1962). Sleeping and Waking. Amsterdam.

Shideman, F. E. (1961). Clin. Pharmacol. Ther., 2, 313.

Tune, G. S. (1968). Brit. med. F., 2, 269.

W.H.O. (1964). Wld Hlth Org. techn. Rep. Ser., No. 273.

Whitlock, F. A., and Lowrey, J. M. (1967). Med. F. Aust., 1, 1157. 